\title{
The South Inylchek Glacier Activity Analysis over a Ten-year Interval in Surface Velocity with Multi- source Spaceborne Imagery
}

\section{Qimin zhang}

China University of Mining and Technology https://orcid.org/0000-0001-8943-7476

\section{Lu Zhang}

Chinese Academy of Sciences

\section{Mingyang Lv}

Chinese Academy of Sciences

\section{Yidan Sun}

China University of Mining and Technology

Shiyong Yan ( $\square$ yanshiyong@cumt.edu.cn )

China University of Mining and Technology

\section{Research Article}

Keywords: South Inylchek Glacier, pixel tracking algorithm, multi-source imagery, glacier velocity, ten-year interval

Posted Date: March 18th, 2021

DOl: https://doi.org/10.21203/rs.3.rs-317482/v1

License: (c) (1) This work is licensed under a Creative Commons Attribution 4.0 International License.

Read Full License

Version of Record: A version of this preprint was published at Environmental Earth Sciences on November 1st, 2021. See the published version at https://doi.org/10.1007/s12665-021-10061-6. 


\section{Abstract}

Ice movement is one of the most important characteristics in describing mountain glacier activity, which is a sensitive natural indicator of climate change. However, the short-term ice movement with a single data source could not precisely and sufficiently demonstrate the response of glaciers to climate change. In order to extract the reliable signal corresponding to climate change, the long-term monitoring of glacier movement should be widely exploited. This paper presents the ice motion distribution of the South Inylchek Glacier by improving pixel tracking algorithm with both synthetic aperture radar and optical imagery in 2007-2008 and 2017-2018. The analysis in spatiotemporal characteristics of the glacier velocity indicates that the South Inylchek Glacier remained almost stable in a ten-year interval with the average velocity of $32 \mathrm{~cm} / \mathrm{d}$, which are computed with quasi-synchronization multi-source imagery. And the consistency of the velocity results was also verified with both optical and SAR imagery during the same period. Therefore, it would be valuable in expanding the research temporal cycle of glacier movement by uniting multi-source data. We also suggest that long-term ice motion should be collected for further analysis in mass balance prediction and assessing the climate change effects in the High Mountain Asia.

\section{Introduction}

With the increase of extreme weather conditions, as a natural indicator of global climate, glaciers in lowlatitude and high-altitude regions have widely gotten people's attention(Kumar et al. 2011; Yellala et al. 2019; Singh et al. 2020). Change monitoring of glacier movement could not only reflect material balance variation and surge, but also acts as a predictor for glacier disasters. Besides, as one of the important characteristics, ice motion is closely related to its mass balance and stability. Furthermore, the long-term monitoring of glacier motion variation around the world would provide better insight into the spatiotemporal evolution of glaciers and global climate change(Paul et al. 2015; Shangguan et al. 2015; Tong et al. 2018).

Currently, most studies of glacier movement are usually performed with a single data source (Paul et al. 2017; Sun et al. 2017; Shukla and Garg 2020), yet data fusion hardly can be seen. In the early stages, the optical imagery with better storage has been widely applied to extract glacier velocity in polar and highaltitude regions(Berthier et al. 2007; Nobakht et al. 2014). Despite its coverage scale and storage capacity, optical imagery is often hampered by inclement weather conditions and the mountain glacier surface partly covered by snow all year-round. It easily leads to an oversaturation phenomenon and destroys the integrity of results(Yan et al. 2019). Instead, many researchers turn to SAR to compute surface displacements, thanks to more launches of radar satellites. SAR imagery with high spatial resolution provides all-time, all-weather services, free from any cloud cover. Besides, SAR imagery with high spatial resolution could be exploited by differential interferometric SAR (D-InSAR), multi-aperture interferometry (MAI), and pixel tracking algorithm(PT) for more accurate glacier flow estimation with the phase and intensity information of SAR images and the external data(Strozzi et al. 2002; Yan et al. 2016; Tong et al. 2018). Spaceborne SAR then has been widely used for the multitemporal analysis of glacier movements, 
yet such existing problems as geometric distortions, the oblique projection and the complex terrain condition would severely limit its application(Berthier et al. 2005).

Generally, the longer the observation temporal period, the more accurate the results revealing the characteristics of climate change. However, it is difficult to meet the requirements of such research with a single data source because of the limitations of satellite in operation and poor image capability. There are few comparative analyses with a temporal interval of more than 10 years in previous studies(Huang and Li 2011; Paul et al. 2017). Nowadays, with the development of remote sensing techniques, we have the ability to carry out ice motion estimation with multi-source imagery for long-term ice investigation. In this paper, both the optical and SAR data with nearly a year interval from 2007-2008 and 2017-2018 are selected respectively and applied for ice motion monitoring. Furthermore, we have also verified the feasibility to extract glacier movement changes and the usability of the PT approach for multi-source imagery. And the evolution of South Inylchek Glacier (SIG) activity will be discussed simultaneously to some extent. All of these might provide a foundation for the long-term time series analysis of large-scale glacier movement study.

\section{Study Area And Datasets \\ 2.1 Study area}

South Inylchek Glacier is located in the Tomur Peak region of the Tianshan Mountains bordering China and Kyrgyzstan, and it is classified as the typical dendritic valley glacier. There is a glacier tongue with an average slope of $2^{\circ}$ (Aizen 2004; Neelmeijer et al. 2014). According to the statistics of the Second Glacier Inventory Dataset of China, the total coverage area is approximately $400 \mathrm{~km}^{2}$ with a length of $64 \mathrm{~km}$ and a width of $3 \mathrm{~km}$ (Hagg et al. 2016). The ice of the study area begins to melt around in March with the temperature rises, and the annual average temperature is about $-7.7^{\circ} \mathrm{C}($ Osmonov et al. 2013). The meltwater of mountain glaciers is the most important freshwater resource for people living downstream because of the Eurasian continental climate with a little rain. Thus, monitoring the SIG movement is of great significance to understand the relationship between ice and climate change in High Mountain Asia (HMA). The detailed image information is shown in Fig. 1, and the glacier outline is described with Randolph Glacier Inventor(RGI) 6.0 in the study region.

\subsection{DataSets}

In this paper, both optical and SAR imagery acquired during the quasi-same period of the 10-year interval from 2007-2008 and 2017-2018 was employed in ice flow estimation respectively, thus the ice motion calculation would be benefited from multi-source datasets. The optical and SAR data were provided by Landsat-5 and ALOS/PALSAR satellites in 2007 to 2008 respectively, while the images tracked during the period of 2017-2018 were from Landsat-8 and Sentinel-1A. The Near Infrared band of 30m spatial resolution was employed with better snow penetration performance of Landsat-5 image, while the OLI panchromatic band imaged by Landsat- 8 with a $15 \mathrm{~m}$ resolution was used(Liu et al. 2020). The relatively 
high spatial resolution is more conducive to reflecting the details of the glacier surface. Besides, L-band ALOS/PALSAR and C-band Sentinel-1A SAR images have been exploited for simultaneous comparative analysis of estimated velocity. Compared with the C-band, the L-band SAR image could present stable characteristics for ice estimation because of its great penetration. Also, both the SRTM DEM and ALOS DEM topographic data were applied to evaluate the elevation changes on the glacier surface, which would be helpful in the analysis of ice dynamics during the monitoring period. Detailed data information is shown in Table 1.

Table 1 Details of the available imagery pairs used for the velocity estimation in this study

\begin{tabular}{|lllll|}
\hline Reference imagery & Search imagery & Sensor & Band & Interval(day) \\
\hline 2007.08 .24 & 2008.07 .11 & ALOS/PALSAR & L & 322 \\
\hline 2007.08 .08 & 2008.08 .10 & Landsat-5/TM & 4 & 368 \\
\hline 2017.07 .20 & 2018.07 .03 & Sentinel-1A & C & 348 \\
\hline 2017.07 .02 & 2018.07 .21 & Landsat-8/OLI & 8 & 384 \\
\hline
\end{tabular}

\section{Method}

The PT method has proved practically useful in mountain glacier velocity extracting(Huang and Li 2011; Yan et al. 2016; Liu et al. 2017). Based on the fundamental hypothesis that the non-glacial region should be stable without movement, the ice motion could be revealed according to patch match information on the glacial area(Neelmeijer et al. 2014). In this paper, the Normalized Cross-Correlation (NCC) algorithm was utilized in image intensity information for offset computation. The sub-pixel level matching results of stable feature points in the non-glacierized regions have been utilized in fitting the geometric transformation model estimation. NCC could achieve high accurate registration in the glacier region by setting reasonable patch window and resample parameters (Giles et al. 2009; Huang and Li 2011; Nobakht et al. 2014). Besides, we improve the traditional algorithm with GPU to realize efficient parallel operations, which would guarantee the timely monitoring of the glacier movement. The data processing flowchart based on PT is shown in Fig. 2.

\subsection{Remove irrelevant information}

The global related offset was mainly brought by the difference in satellite attitude and position during the imaging process. Generally, the quadratic polynomial fit is capable of covering the global deformation(Yan et al. 2019). To precisely obtain the deformation model, the Random Sample Consensus (RANSAC) algorithm was adopted for more accurate calculation of coefficient. During the observation period, we assumed that there was no displacement in most regions of the image, then the transformation model parameters would be efficiently revealed and the orbit-related offset could be accurately removed. 
Besides, the topographic-related offset would appear due to the different imaging angles in mountain regions, and this phenomenon might be serious in SAR images because of its oblique project. To be specific, the azimuth offset is greatly impacted by the intersection angle for orbits and the sensor incidence angle, while the offset along the range direction is proportional to the perpendicular baseline. For SAR imagery, the offset along the azimuth and range directions should be calculated for terrain compensation and an external DEM(Riveros et al. 2013; Yan et al. 2013). And orthorectification would be utilized for optical imagery to remove the terrain displacement. With the assistance of the RPC (Rational Polynomial Coefficient) information of optical images itself and external DEM data, more accurate motion information would be obtained.

After non-glacial motion compensation or removal, the residual and error mismatch points of coregistration might remain. Therefore, the filter operation was needed for reducing the effect of the highfrequency noise. Given both the noise and the edge information belong to the high-frequency signal, the Ranked-order based Adaptive Median Filter (RAMF) was employed for smoothing and de-noising to retain the details(Yan et al. 2019). RAMF works well in ice motion estimation, as it could not just ensure the accuracy of offset, but also properly filter the noise.

\subsection{Velocity decomposition}

In terms of a geometric difference of projection between SAR and optical data, to make a consistent comparison, all images we used must refer to the same coordinate system before extracting the glacier velocity, which is an essential geometric basis for the comparative analysis of multi-source imagery. To deliver a clearer analysis, the SAR slant range image was decomposed into the plane coordinate system. Given that the terrain of the study area is basically even and smooth gently, we assume that the glacier movement was parallel to the local slope and consistent with the direction in which this maximum slope occurred. The geometric relationship model of SAR image forming is shown in Fig. 3, and the arrow direction is defined as the positive direction in the figure ( $\mathrm{Ng}$ et al. 2012).

From the geometric relationship of SAR imaging we could get this formula:

$$
D_{\text {Los }}=D_{H} \sin \theta-D_{V} \cos \theta
$$

Where $D_{\text {Los }}$ is the surface displacement of the ground point $P$ at the line of sight(LOS), $D_{H}$ and $D_{V}$ are the ground-range (GR) and vertical displacement respectively, and $\theta$ is the sensor incidence angle at the reflection point. In this paper, the influence of the glacier deformation in the vertical direction could be reasonably ignored because it has a little contribution to slight displacement (Neelmeijer et al. 2014; Shangguan et al. 2015). $D_{\text {Los }}$ could be regarded as the combination of east-west and north-south displacements on the horizontal plane(Yang et al. 2020a).

$$
D_{H}=D_{E} \cos \alpha-D_{N} \sin \alpha
$$


Where $D_{N}$ is the north-south displacement of the ground point, $D_{E}$ is the east-west deformation, and $a$ is the azimuth of the satellite heading vector (positive clockwise from north). To solve the $D_{N}$ and $D_{E}$, the geometric relationship between the azimuth and the horizontal deformation has been established.

$$
D_{A \succeq i}=D_{N} \cos \alpha+D_{E} \sin \alpha
$$

Where, $D_{A Z i}$ is the ground point deformation along the azimuth direction. With the above formulas, the offset of the SAR image in the east-west and the north-south direction could be obtained.

\section{Results And Analysis}

The surface movement information of the SIG from 2017 to 2018 was computed based on the Landsat-8 and Sentinel-1A data with the improved PT algorithm as shown in Fig. 4 (positive value refers to velocities toward the east and north, while negative value refers to the opposite direction). The results show that the ice velocity in the same direction obtained from different data sources was roughly uniform, which was about $30 \mathrm{~cm} / \mathrm{d}$ in the east-west direction and about $5 \mathrm{~cm} / \mathrm{d}$ in the north-south direction in 2017-2018. This verifies the feasibility of the geometric conversion based on multi-source heterogeneous images.

The Landsat-5 and ALOS/PALSAR data of quasi-same period have been applied in ice motion estimation of 2007-2008 and corresponding results are shown in Fig. 5. The velocity in the east-west direction proves basically the same despite different data sources. Yet the offset in the north-south direction is less obvious because of the small angle between the direction of north and the direction in which SAR satellite flies. And the inversion results are impacted greatly by noises(Helanow et al. 2020; Yang et al. 2020b). Besides, the L-band ALOS/PASAR data could better reflect the details of the glacier movement because of the excellent penetrability, but the decorrelation of the Landsat- 5 image leads to the large differences of velocity in the north-south direction.

\subsection{Comparative analysis of glacier movement}

The total velocity on the glacier surface was obtained by the combination of ice motion along with different directions (Fig. 6). And the ranges of the color bars were unified $(0 \mathrm{~cm} / \mathrm{d}$ to $50 \mathrm{~cm} / \mathrm{d})$ for highlighting the features of ice motion. The velocity changes and elevation differences along the profile line $A B$ (black line in Fig. 1) on the glacier tongue are shown in Fig 7. A comprehensive analysis of the glacier movement between 2007-2008 and 2017-2018 yields that the velocity distribution looks similar on the profile. Generally, most ice velocities could achieve 25 to $35 \mathrm{~cm} / \mathrm{d}$ on the ice surface. And it decreases gradually from the upper part to the down part. At a distance of $7.5 \mathrm{~km}$ from the initial point along profile $A B$, there is an extreme velocity was observed at the fork with high velocity along the middle line because of the friction from the surrounding mountains. Such velocity distribution shows a satisfying agreement 
with the result in the previous study(Neelmeijer et al. 2014; Nobakht et al. 2014; Mayer et al. 2016; Yan et al. 2018).

To understand the relationship between the ice mass variation and the glacier velocity, the elevation change along the profile on the glacier surface would be obtained(Fig. 7) with both SRTM DEM and ALOS DEM(Shean et al. 2016). It indicates that the elevation of the upper and middle reaches has barely changed during around 10 years while the downstream area saw the largest variation. First, the reduction of elevation leads to a decrease of gravitational potential energy (GPE) yet an increase of kinetic energy (KE). Meanwhile, glaciers from the middle and upper reaches of the glacier are constantly transported the downstream area, and the accumulated stress is released centrally at the fork, this means that the bedrock may be eroded worse at the bottom of the glacier and more likely to move. Finally, the height difference would further increase due to inertia; Second, a large amount of glacial meltwater may flow into Lake Merzbacher during the ablation season, leaving the lake level rising rapidly and much ice becoming floating after being split off. It may cause the loss of mass at the ice front, prompting the glacier motion to accelerate for replenishment. A similar monitoring result also could be seen in previous studies(Mayer et al. 2016; Li et al. 2018). The accumulation of moraine leads to a slow increase in elevation to the terminus, and the motion velocity decreases gradually when the glacier flows toward the west, which is consistent with the glacier dynamics. The elevation change of the glacier region is relatively small in the study period (Fig. 7), and it could be seen that it is reasonable to ignore the vertical displacement in this paper. Although the research period between the remote imagery and the elevation data is not completely consistent, we found that the elevation curve presents stability in general except for large variation around the turning points (Fig. 7). Therefore, the whole glacier could be generally considered as being in a state of mass balance.

As Figs. 4-6 show, there is an obvious discontinuity phenomenon in the upstream region of ice motion fields, which is mainly caused by the saturation associated with the high albedo of clean ice(Yan et al. 2018). Although the large matching window was selected to perfect the Signal-to-Noise Ratio(SNR), the velocity information might be lost at the edge of the glacier at the same time. In order to analyze the ice motion better in downstream of the glacier, the flow velocity contours have been shown in Fig. 8 . Propelled by surface in middle and upper stream, the glacier branch tuning to Lake Merzbacher releases force at the mouth of the lake, causing a stretch at the bottom of the glacier. Here the contours are dense and the glacier velocity changes drastically. There is a large amount of debris on the terminus, which may block the motion of the glacier and be clearly observed in the optical image. In addition, there is a relatively long distance with a gentle slope, causing the glacier velocity to decrease gradually from upstream to downstream. The velocity changes above are consistent with the distribution of moraines as shown in the high-resolution remote sensing images (Fig. 8).

\subsection{Accuracy estimation}


In this paper, the velocity along the same direction respectively from the SAR and optical imagery were compared for the accuracy estimation. And the consistency of the velocity of multi-source images has been also verified. The velocity difference along the profile line in Fig. 1 is shown in Fig. 9. It presents that the velocity fields from multi-source data in different directions are the same in general. Besides, the rationality of the slant-range conversion of SAR data has been verified as the difference of ice flow rate was $\pm 2 \mathrm{~cm} / \mathrm{d}$ in $2017-2018$ based on the data of Landsat-8 and Sentinel-1A, which is much smaller than the average velocity. By comparison, the velocity difference could achieve around $\pm 7 \mathrm{~cm} / \mathrm{d}$ in the northsouth direction during 2007-2008. The Near Infrared band of Landsat-5 is insensitive to the glacier variation because of the low resolution, while the L-band ALOS/PALSAR of $5 \mathrm{~m}$ full resolution could perform better in permeability. Therefore, there is a large difference in the ice motion revealed on the glacier surface between the Landsat- 5 and PALSAR.

Based on the assumption that there is no movement in the ice-free region in the estimated velocity field, the Root Mean Square Error (RMSE) would be statically computed for evaluating monitoring accuracy (Table 2). And it is roughly the same as the results described by the previous research(Shangguan et al. 2015). The RMSE of the ice-free region obtained by Landsat- 5 images is larger than that of others, taking into account the resolution and other reasons, the experimental result proves valid and acceptable with a high degree of reliability. To ensure the accuracy of the final monitoring results, in this paper, the SRTM data has been adopted for the topographic correction. Besides, the remote sensing images were registered based on the NCC algorithm, which would guarantee the accuracy of co-registration within 0.1 pixels(Ernesto Rodríguez 2006; Mayer et al. 2016).

Table 2 Accuracy of the velocity extracted from different data

\begin{tabular}{|llll|}
\hline Sensor & $\begin{array}{l}\text { east-west direction } \\
\text { RMSE/(cm/d) }\end{array}$ & $\begin{array}{l}\text { north-south direction } \\
\text { RMSE/(cm/d) }\end{array}$ & $\begin{array}{l}\text { Synthetic } \\
\text { direction } \\
\mathrm{RMSE} /(\mathrm{cm} / \mathrm{d})\end{array}$ \\
\hline ALOS/PALSAR & 0.78 & 1.23 & 1.41 \\
\hline Landsat-5 & 2.39 & 1.86 & 3.00 \\
\hline Sentinel-1A & 0.22 & 0.44 & 0.44 \\
\hline Landsat-8 & 0.81 & 0.88 & 1.19 \\
\hline
\end{tabular}

\section{Discussion}

In this study, the SIG velocity has been computed with both Landsat-8 and Sentinel-1A data in 2017-2018 by the PT algorithm. And the velocity results of different data sources show good consistency in glacier movement. The reliability of the ice motion estimation approach from multi-source was also proved by the comparison of the results in 2007-2008. Obviously, the integration of multi-source imagery would extend the monitoring period and overcome the shortcomings associated with a single data source. 
However, in the middle part of the glacial trunk, the velocity deviation of the imagery of quasisynchronization is varied largely. And the corresponding reasons are summarized as follows.

(1) Difference in penetration performance. Penetration capabilities of different types of sensors are variable on the glacier surface, and the SAR sensors could achieve deeper than that of the optical sensors. But, there is a little difference in the ice motion of the quasi-same period, which proves that the ice motions were little affected by the penetration in the study area. Due to the limits of achieved remote sensing imagery, the acquisition date of imagery used in ice motion estimation is not the same, as well as the spatial resolution. Both of them would affect the consistency in ice velocity distribution of different data sources. Besides, different penetration capability for C-band Sentinel-1A and L-band ALOS/PALSAR would also bring the variation indifference of ice motions(Strozzi et al. 2008; Yellala et al. 2019; Jefriza et al. 2020).

(2) Difference in the research period. The time interval of one year for each image would facilitate the ice motion calculation and comparison. However, with a different revisit time of satellites and the severely affected optical imagery by weather conditions, the images we could select have more restricted conditions. Meanwhile, the variations in spatial and temporal characteristics happen all-time on the ice surface, which affects the consistency of the ice velocity results in a long temporal baseline.

(3) Difference in the data processing. There is a great difference in terrain correction for SAR and optical imagery due to their different imaging geometry. The optical data was orthorectified with the PRC information and an external DEM for compensating the topographic effect. Meanwhile, with the assistance of DEM and orbit parameters on the PT method, the topographic affection could be accurately compensated in the ice motion estimation. Besides, the incidence angle of the SAR sensor would change under different topographic regions, and the reliability of the decomposition model formula in the 3.2 section needs to be verified further.

\section{Conclusion}

In this study, the spatio-temporal distributions of ice motion of SIG were yielded by the improved PT algorithm with optical and SAR imagery during the quasi-same period of the 10-year interval. The results comparison of different datasets with different temporal intervals were given and thoroughly analyzed, which would be of great importance to ice activity and climate change research in the Tian Shan.

The velocity comparison reveals that there is no significant variation of ice motion during $2007 / 2008$ $2017 / 2018$. Only ice motion change in the upper and middle parts of the glacier is generally larger than that in the lower part of stream. The rapidly increased movement can be observed at the fork in the downstream, where the maximum elevation change occurs. The observed average ice velocity ranges from 30 to $35 \mathrm{~cm} / \mathrm{d}$, which proves that the movement of glacier surfaces could be accurately estimated by the PT method with both optical and SAR imagery. Furthermore, a combination of imagery acquired by different sensors would be helpful in detecting the glacial movement changes, which would provide an important guarantee for long-term ice motion analysis. Besides, the RMSE of 0.1 pixels of the average ice 
velocity on the ice-free region verifies the reliability of extracting glacier motion velocity with the multisource imagery.

With the greatly improved spatial and temporal resolution of SAR and optical imagery, an effective and robust way for both long-term ice motion analysis and regular glacier resource investigation would be provided. In future research, the meteorological documentation and the more accurate DEM data would be also exploited, which could support the analysis of consistent interannual changes in glacier activity along with climate variation in central Asia.

\section{Declarations}

Acknowledgments This work was supported by the National Natural Science Foundation of China under Grant 41876226 and the Strategic Priority Research Program of the Chinese Academy of Sciences under Grant XDA19070202. The European Space Agency (ESA) provided the IW mode SAR imagery free of charge, the ALOS/PALSAR images employed were archived and provided by the Japan Aerospace Exploration Agency (JAXA), and the Landsat images employed were archived by the United States Geological Survey (USGS), thanks for those agencies.

\section{References}

Aizen VB (2004) Association between atmospheric circulation patterns and firn-ice core records from the Inilchek glacierized area, central Tien Shan, Asia. Journal of Geophysical Research 109 doi:10.1029/2003jd003894

Berthier E, Arnaud Y, Kumar R, Ahmad S, Wagnon P, Chevallier P (2007) Remote sensing estimates of glacier mass balances in the Himachal Pradesh (Western Himalaya, India). Remote Sensing of Environment 108:327-338 doi:10.1016/j.rse.2006.11.017

Berthier E et al. (2005) Surface motion of mountain glaciers derived from satellite optical imagery. Remote Sensing of Environment 95:14-28 doi:10.1016/j.rse.2004.11.005

Ernesto Rodríguez CSM, and J. Eric Belz (2006) A Global Assessment of the SRTM. Photogrammetric Engineering \& Remote Sensing 72:249-260 doi:10.14358/PERS.72.3.249

Giles AB, Massom RA, Warner RC (2009) A method for sub-pixel scale feature-tracking using Radarsat images applied to the Mertz Glacier Tongue, East Antarctica. Remote Sensing of Environment 113:16911699 doi:10.1016/j.rse.2009.03.015

Hagg W, Mayer C, Lambrecht A, Helm A (2016) Sub-debris melt rates on southern inylchek glacier, central tian shan. Geografiska Annaler 90:55-63 doi:10.1111/j.1468-0459.2008.00333.x

Helanow C, Iverson NR, Zoet LK, Gagliardini O (2020) Sliding Relations for Glacier Slip With Cavities Over Three-Dimensional Beds. Geophysical Research Letters 47 doi:10.1029/2019gl084924 
Huang L, Li Z (2011) Comparison of SAR and optical data in deriving glacier velocity with feature tracking. Int J Remote Sens 32:2681-2698 doi:10.1080/01431161003720395

Jefriza, Yusoff IM, Abir IA, Syahreza S, Rusdi M, Razi P, Lateh H (2020) Application of Time-Series Sentinel-1A for Land Deformation in Central Aceh, Indonesia. IOP Conference Series: Earth and Environmental Science 572:012035 doi:10.1088/1755-1315/572/1/012035

Kumar V, Venkataramana G, Høgda KA (2011) Glacier surface velocity estimation using SAR interferometry technique applying ascending and descending passes in Himalayas. International Journal of Applied Earth Observation and Geoinformation 13:545-551 doi:10.1016/j.jag.2011.02.004

Li J, Li ZW, Wu LX, Xu B, Hu J, Zhou YS, Miao ZL (2018) Deriving a time series of 3D glacier motion to investigate interactions of a large mountain glacial system with its glacial lake: Use of Synthetic Aperture Radar Pixel Offset-Small Baseline Subset technique. Journal of Hydrology 559:596-608 doi:10.1016/j.jhydrol.2018.02.067

Liu Q, Mayer C, Wang X, Nie Y, Wu KP, Wei JF, Liu SY (2020) Interannual flow dynamics driven by frontal retreat of a lake-terminating glacier in the Chinese Central Himalaya. Earth and Planetary Science Letters 546 doi:10.1016/j.epsl.2020.116450

Liu TT, Niu MY, Yang YD (2017) Ice Velocity Variations of the Polar Record Glacier (East Antarctica) Using a Rotation-Invariant Feature-Tracking Approach. Remote Sens-Basel 10 doi:10.3390/rs10010042

Mayer C, Lambrecht A, Hagg W, Helm A, Scharrer K (2016) Post-drainage ice dam response at lake merzbacher, inylchek glacier, kyrgyzstan. Geografiska Annaler 90:87-96 doi:10.1111/j.1468-

0459.2008.00336.x

Neelmeijer J, Motagh M, Wetzel H-U (2014) Estimating Spatial and Temporal Variability in Surface Kinematics of the Inylchek Glacier, Central Asia, using TerraSAR-X Data. Remote Sens-Basel 6:9239-9259 doi:10.3390/rs6109239

Ng AH-M, Ge LL, Zhang K, Li XJ (2012) Estimating horizontal and vertical movements due to underground mining using ALOS PALSAR. Engineering Geology 143-144:18-27 doi:10.1016/j.enggeo.2012.06.003

Nobakht M, Motagh M, Wetzel H-U, Roessner S, Kaufmann H (2014) The Inylchek Glacier in Kyrgyzstan, Central Asia: Insight on Surface Kinematics from Optical Remote Sensing Imagery. Remote Sens-Basel 6:841-856 doi:10.3390/rs6010841

Osmonov A, Bolch T, Xi C, Kurban A, Guo WQ (2013) Glacier characteristics and changes in the Sary-Jaz River Basin (Central Tien Shan, Kyrgyzstan) - 1990-2010. Remote Sensing Letters 4:725-734 doi:10.1080/2150704x.2013.789146

Paul F et al. (2015) The glaciers climate change initiative: Methods for creating glacier area, elevation change and velocity products. Remote Sensing of Environment 162:408-426 
Paul F, Strozzi T, Schellenberger T, Kääb A (2017) The 2015 Surge of Hispar Glacier in the Karakoram. Remote Sens-Basel 9 doi:10.3390/rs9090888

Riveros N, Euillades L, Euillades P, Moreiras S, Balbarani S (2013) Offset tracking procedure applied to high resolution SAR data on Viedma Glacier, Patagonian Andes, Argentina. Advances in Geosciences 35:7-13 doi:10.5194/adgeo-35-7-2013

Shangguan DH, Bolch T, Ding YJ, Kröhnert M, Pieczonka T, Wetzel HU, Liu SY (2015) Mass changes of Southern and Northern Inylchek Glacier, Central Tian Shan, Kyrgyzstan, during \&sim;1975 and 2007 derived from remote sensing data. The Cryosphere 9:703-717 doi:10.5194/tc-9-703-2015

Shean DE, Alexandrov O, Moratto ZM, Smith BE, Joughin IR, Porter C, Morin P (2016) An automated, opensource pipeline for mass production of digital elevation models (DEMs) from very-high-resolution commercial stereo satellite imagery. ISPRS Journal of Photogrammetry and Remote Sensing 116:101117 doi:10.1016/j.isprsjprs.2016.03.012

Shukla A, Garg PK (2020) Spatio-temporal trends in the surface ice velocities of the central Himalayan glaciers, India. Global and Planetary Change 190 doi:10.1016/j.gloplacha.2020.103187

Singh G, Nela BR, Bandyopadhyay D, Mohanty S, Kulkarni AV (2020) Discovering anomalous dynamics and disintegrating behaviour in glaciers of Chandra-Bhaga sub-basins, part of Western Himalaya using DInSAR. Remote Sensing of Environment 246:111885 doi:10.1016/j.rse.2020.111885

Strozzi T, Kouraev A, Wiesmann A, Wegmüller U, Sharov A, Werner C (2008) Estimation of Arctic glacier motion with satellite L-band SAR data. Remote Sensing of Environment 112:636-645 doi:10.1016/j.rse.2007.06.007

Strozzi T, Luckman A, Murray T, Wegmüller U, Werner CL (2002) Glacier Motion Estimation Using SAR Offset-Tracking Procedures. IEEE Transactions on Geoscience and Remote Sensing 40:2384-2391 doi:10.1109/TGRS.2002.805079

Sun YL, Jiang LM, Liu L, Sun YF, Wang HS (2017) Spatial-Temporal Characteristics of Glacier Velocity in the Central Karakoram Revealed with 1999-2003 Landsat-7 ETM+ Pan Images. Remote Sens-Basel 9:1064 doi:10.3390/rs9101064

Tong XH et al. (2018) Multi-track extraction of two-dimensional surface velocity by the combined use of differential and multiple-aperture InSAR in the Amery Ice Shelf, East Antarctica. Remote Sensing of Environment 204:122-137 doi:10.1016/j.rse.2017.10.036

Yan SY, Guo HD, Liu G, Ruan ZX (2013) Mountain glacier displacement estimation using a DEM-assisted offset tracking method with ALOS/PALSAR data. Remote Sensing Letters 4:494-503 doi:10.1080/2150704x.2012.754561 
Yan SY, Li Y, Li ZG, Liu G, Ruan ZX, Li Z (2018) An insight into the surface velocity of Inylchek Glacier and its effect on Lake Merzbacher during 2006-2016 with Landsat time-series imagery. Environ Earth Sci 77:773 doi:10.1007/s12665-018-7964-7

Yan SY, Ruan ZX, Liu G, Deng KZ, Lv MY, Perski Z (2016) Deriving Ice Motion Patterns in Mountainous Regions by Integrating the Intensity-Based Pixel-Tracking and Phase-Based D-InSAR and MAI Approaches: A Case Study of the Chongce Glacier. Remote Sens-Basel 8 doi:10.3390/rs8070611

Yan SY, Zheng YT, Li Y, Lang FK, Ruan ZX (2019) A spatio-temporal variation analysis of Fedchenko and Grumm-Grzhimaylo glacier motion pattern with an efficient pixel-tracking method on spaceborne SAR imagery. Environ Earth Sci 78:599 doi:10.1007/s12665-019-8610-8

Yang LY, Zhao CY, Lu Z, Yang CS, Zhang Q (2020a) Three-Dimensional Time Series Movement of the Cuolangma Glaciers, Southern Tibet with Sentinel-1 Imagery. Remote Sens-Basel 12 doi:10.3390/rs12203466

Yang W et al. (2020b) Seasonal Dynamics of a Temperate Tibetan Glacier Revealed by High-Resolution UAV Photogrammetry and In Situ Measurements. Remote Sens-Basel 12:2389 doi:10.3390/rs12152389

Yellala A, Kumar V, Høgda KA (2019) Bara Shigri and Chhota Shigri glacier velocity estimation in western Himalaya using Sentinel-1 SAR data. Int J Remote Sens 40:5861-5874

doi:10.1080/01431161.2019.1584685

\section{Figures}




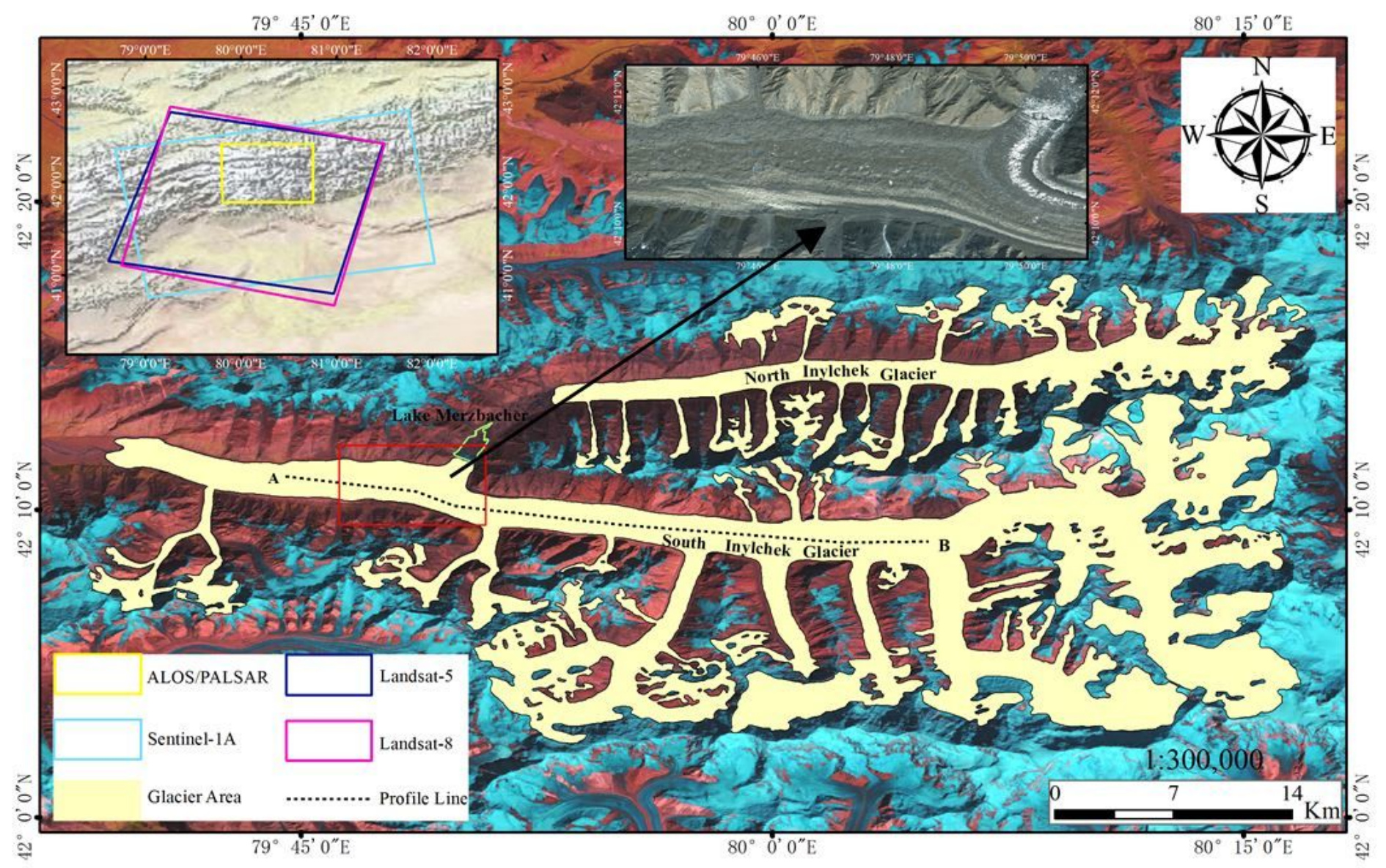

\section{Figure 1}

South Inylchek Glacier overlayed on Landsat-8 OLI image from 21 July 2018 and the corresponding location of the study region is presented in the left inset

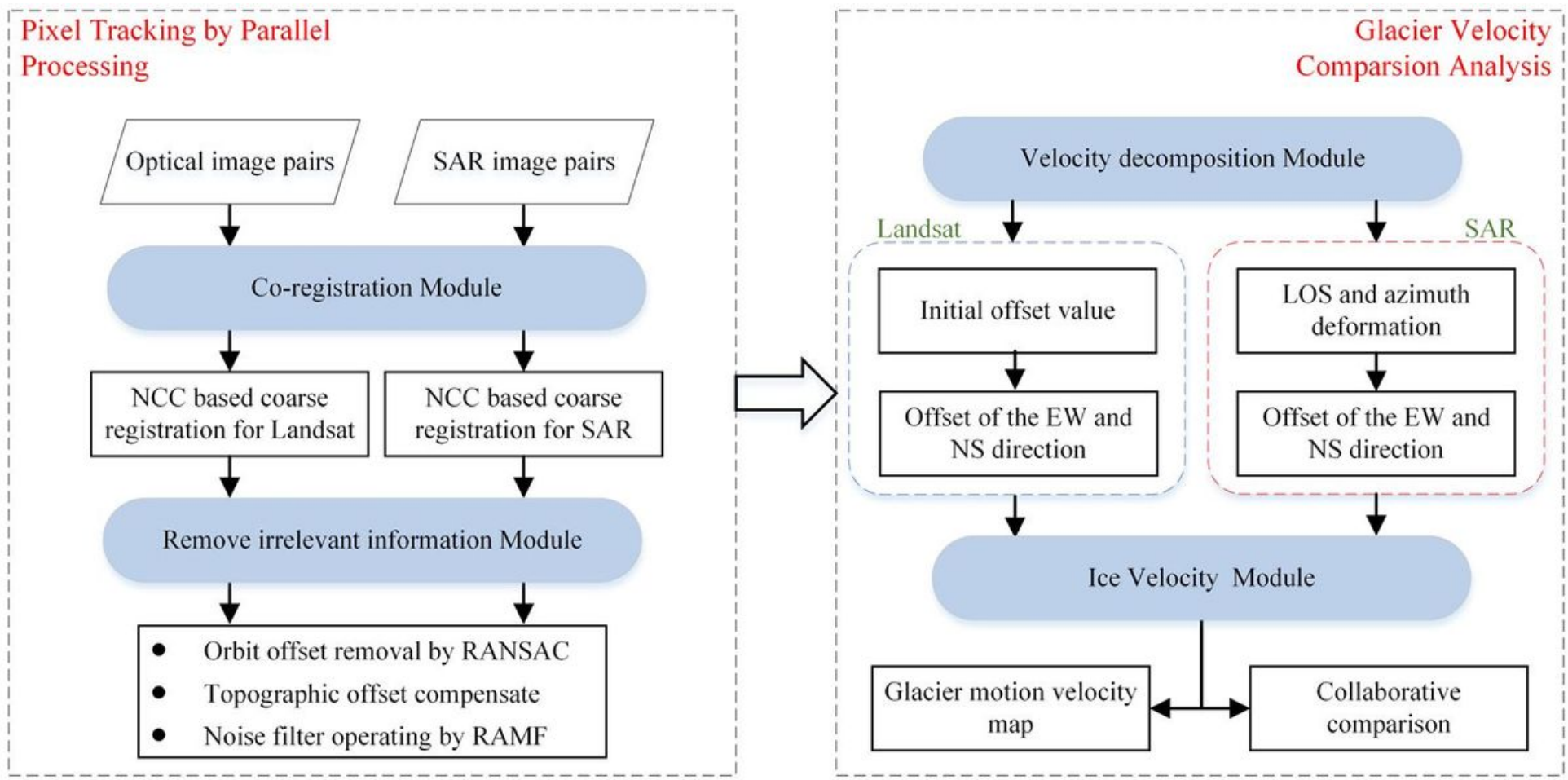


Figure 2

Flowchart of glacier velocity extraction and comparison

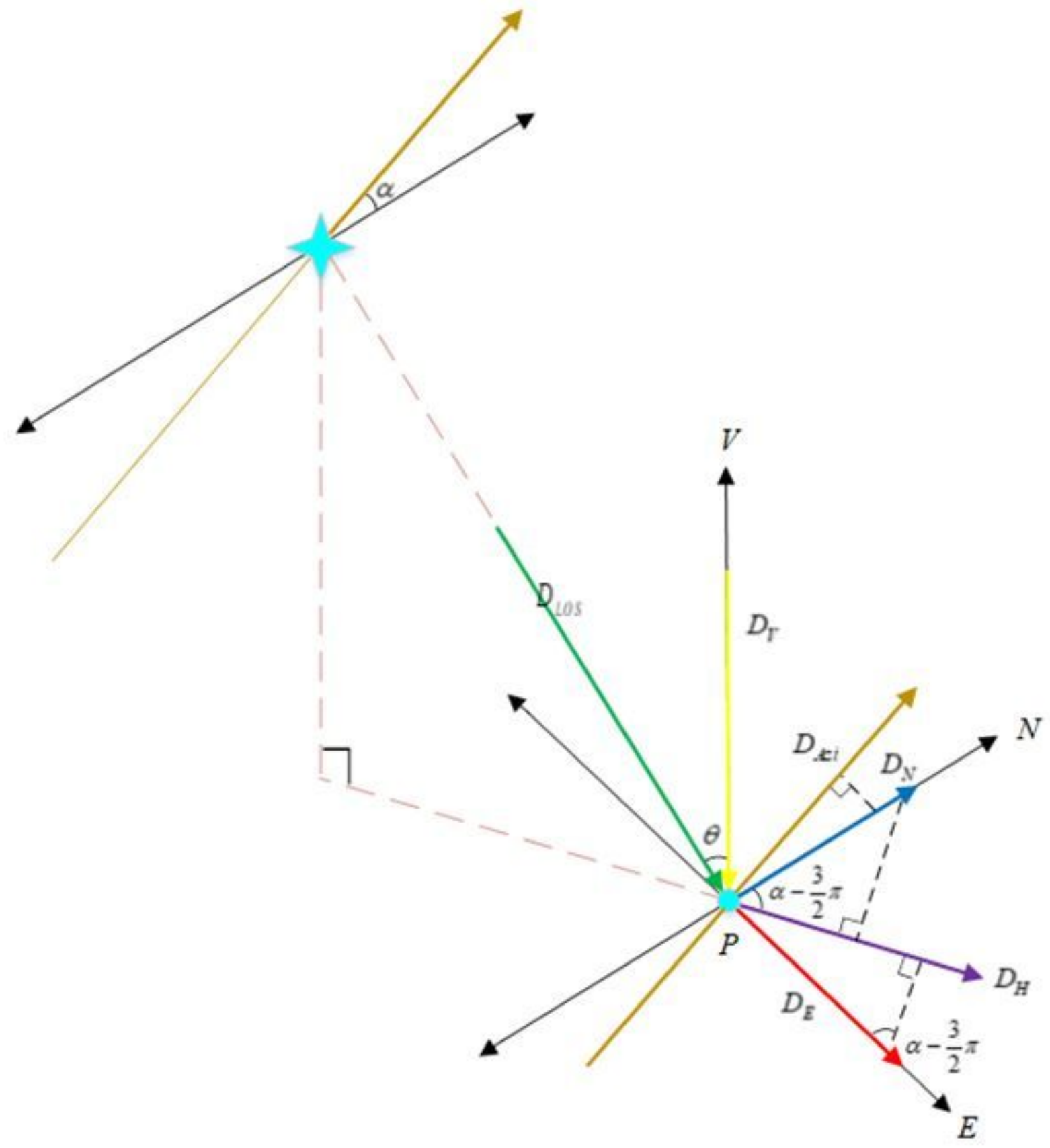

Figure 3

Decomposition of the displacement vector along the line of sight 


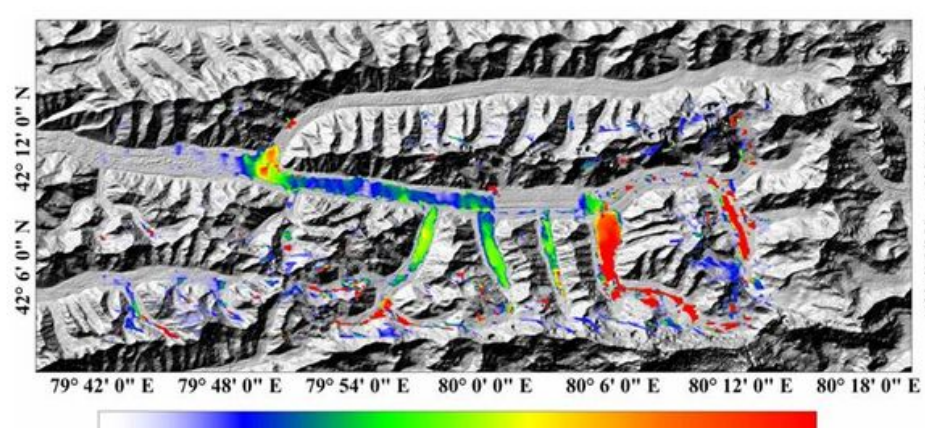

10

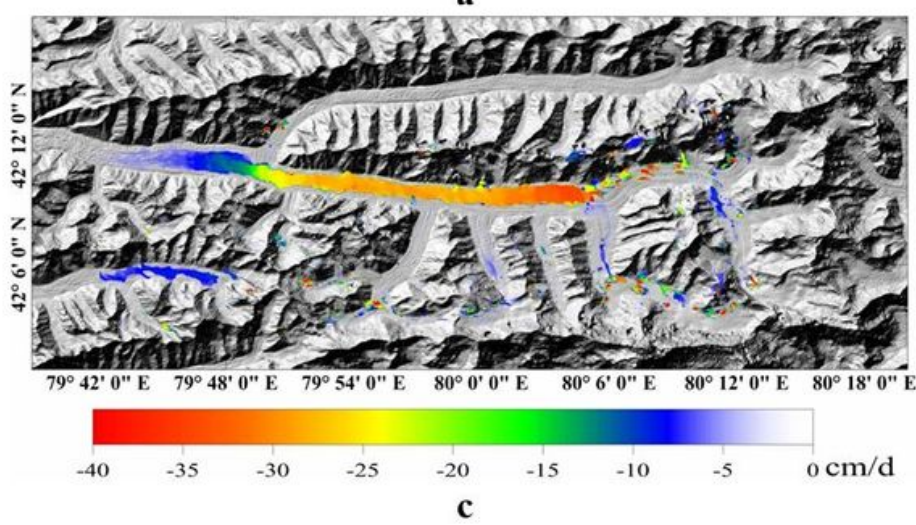

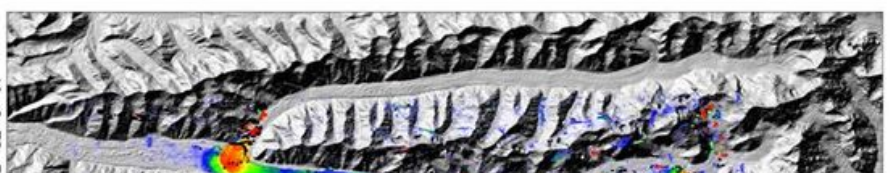

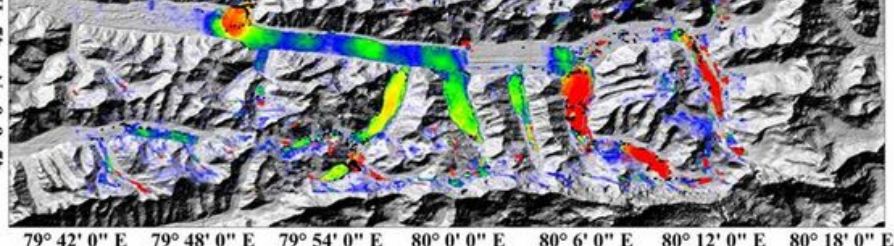

b

Figure 4

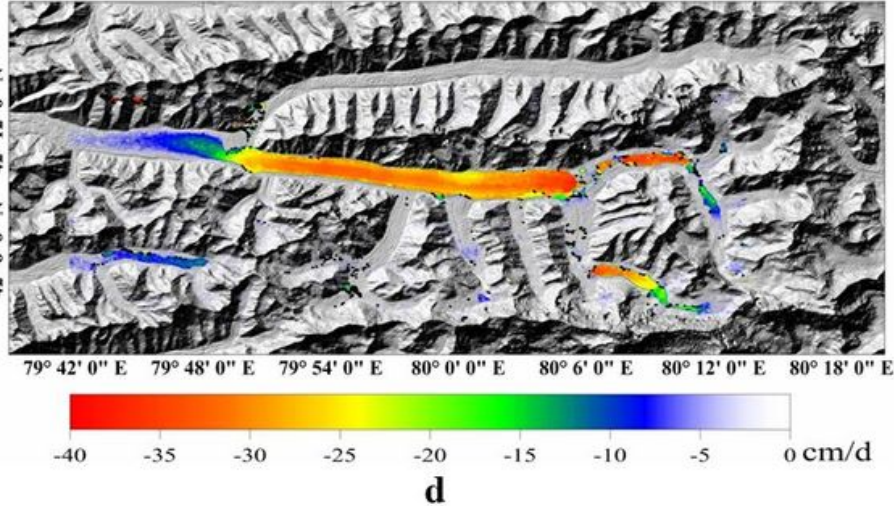

The average glacier velocity field in different directions from 2017 to 2018. (a) The velocity in a northsouth direction of Sentinel-1A; (b) The velocity in a north-south direction of Landsat-8; (c) The velocity in an east-west direction of Sentinel-1A; (d) The velocity in an east-west direction of Landsat-8

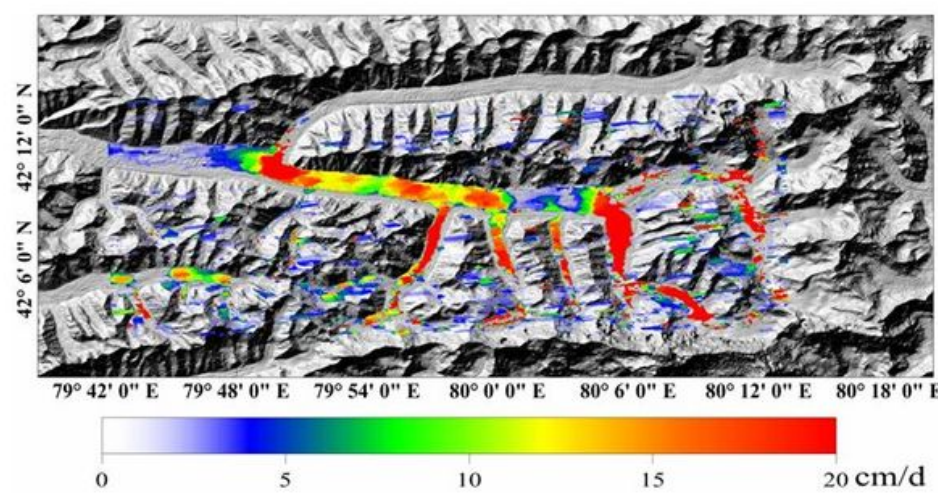

a

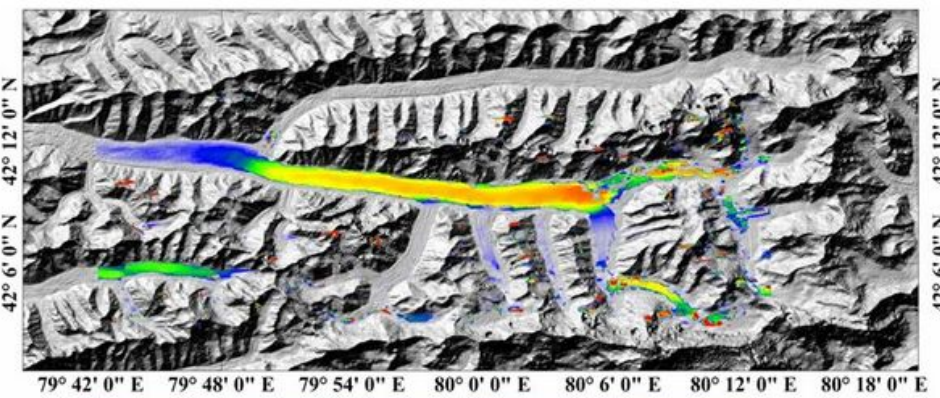

$-40$

$-35$

$-20$

c

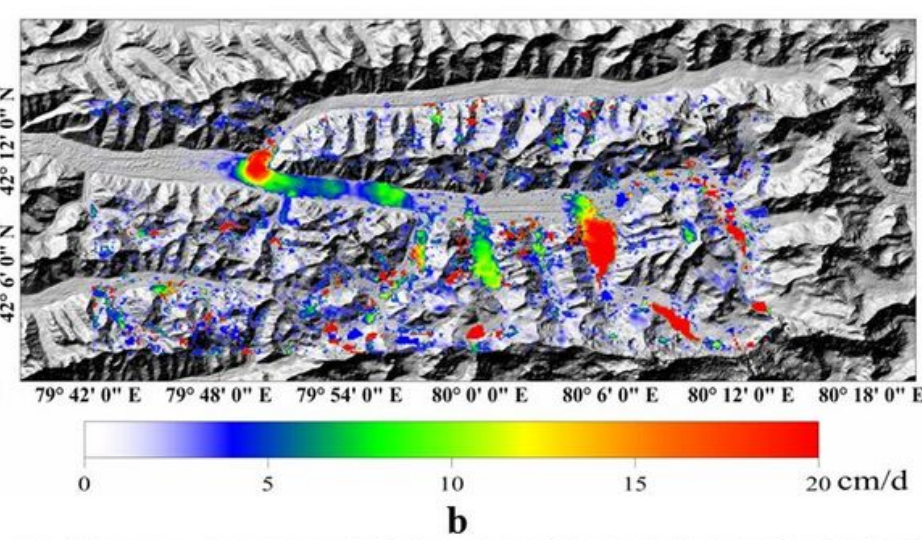

ED

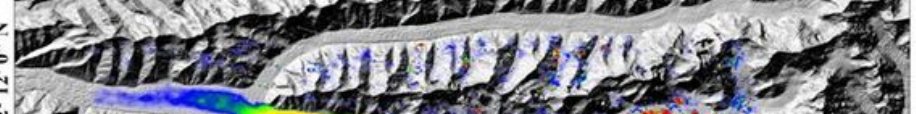

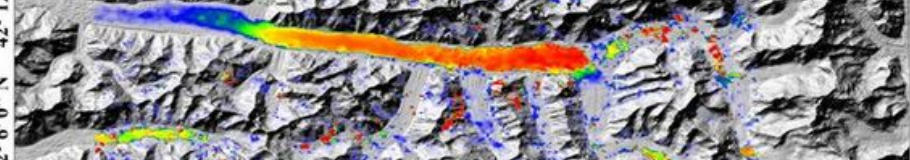

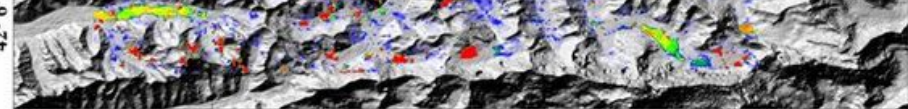

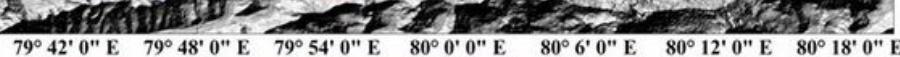

$\begin{array}{lllllllll}-40 & -35 & -30 & -25 & -20 & -15 & -10 & -5 & 0 \mathrm{~cm} / \mathrm{d}\end{array}$ 


\section{Figure 5}

The estimated average glacier velocity field in different directions from 2007 to 2008. (a) The velocity in a north-south direction of ALOS/PALSAR; (b) The velocity in a north-south direction of Landsat-5; (c) The velocity in an east-west direction of ALOS/PALSAR; (d) The velocity in an east-west direction of Landsat-5
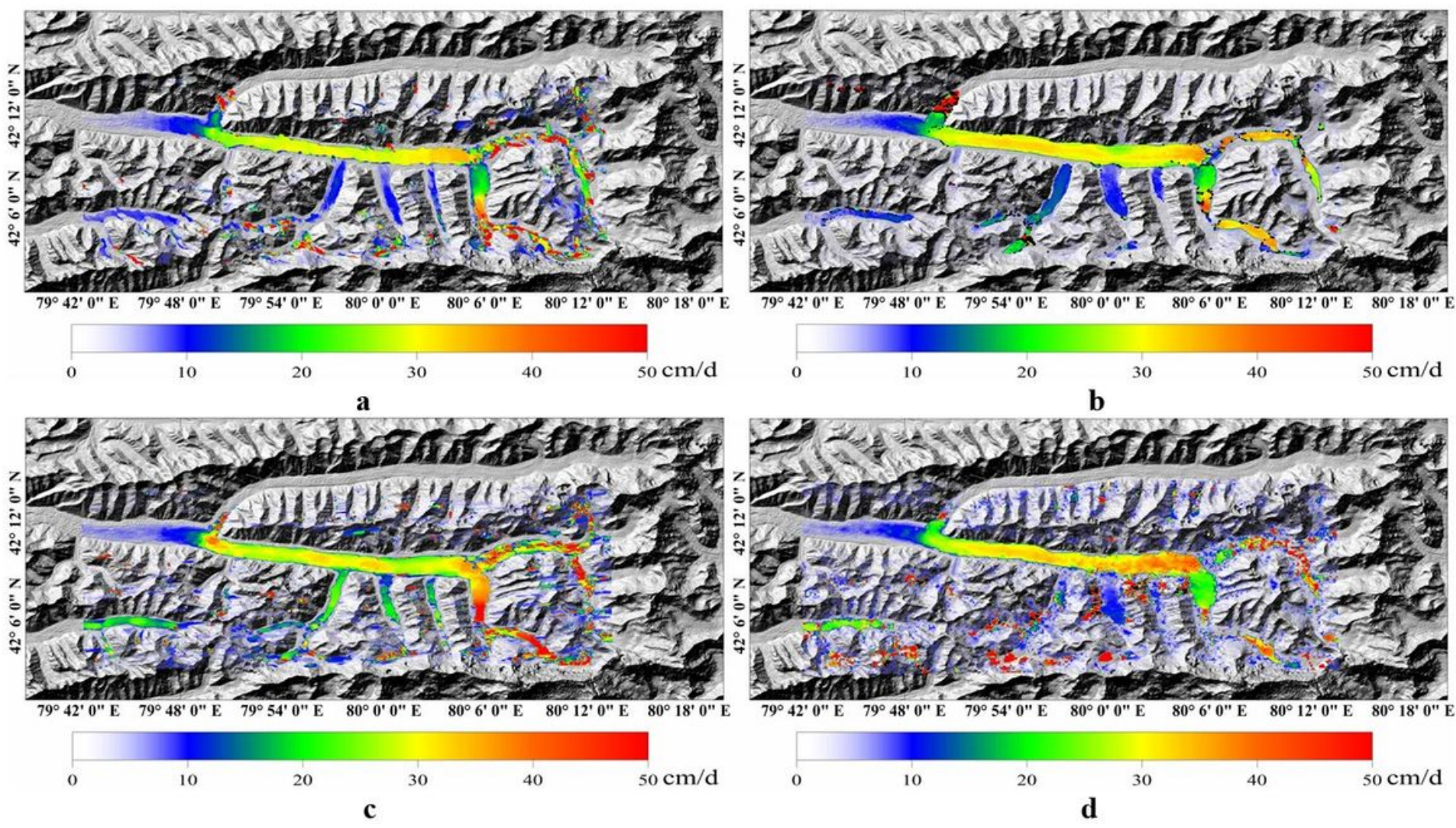

Figure 6

The estimated average glacier velocity field from multi-source imagery in 2017-2018 and 2007-2008. (a) The velocity extracted by Sentinel-1A; (b) The velocity extracted by Landsat-8; (c) The velocity extracted by ALOS/PALSAR; (d) The velocity extracted by Landsat- 5 


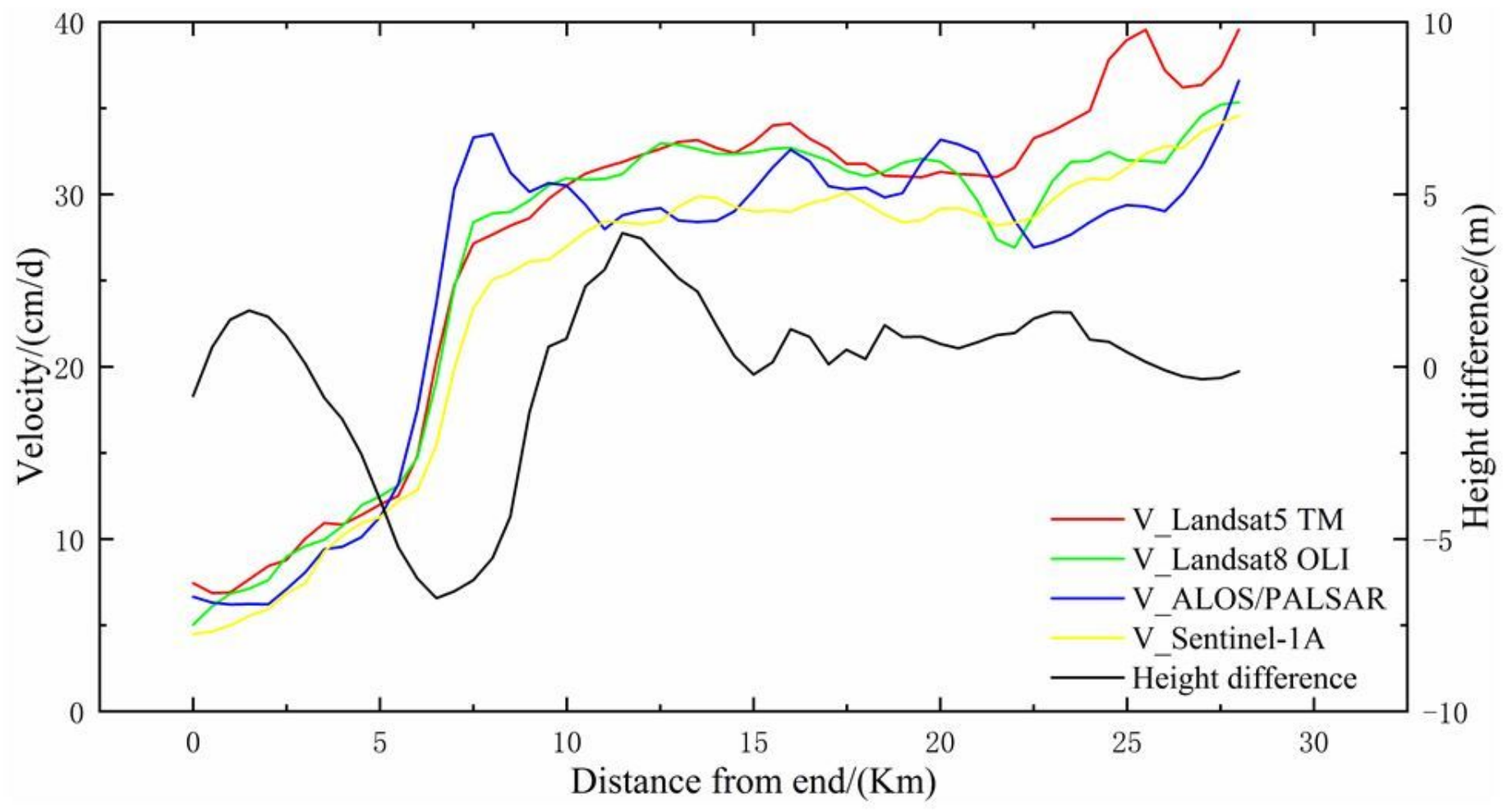

Figure 7

Profiles of glacier velocity from different images and corresponding height difference variations
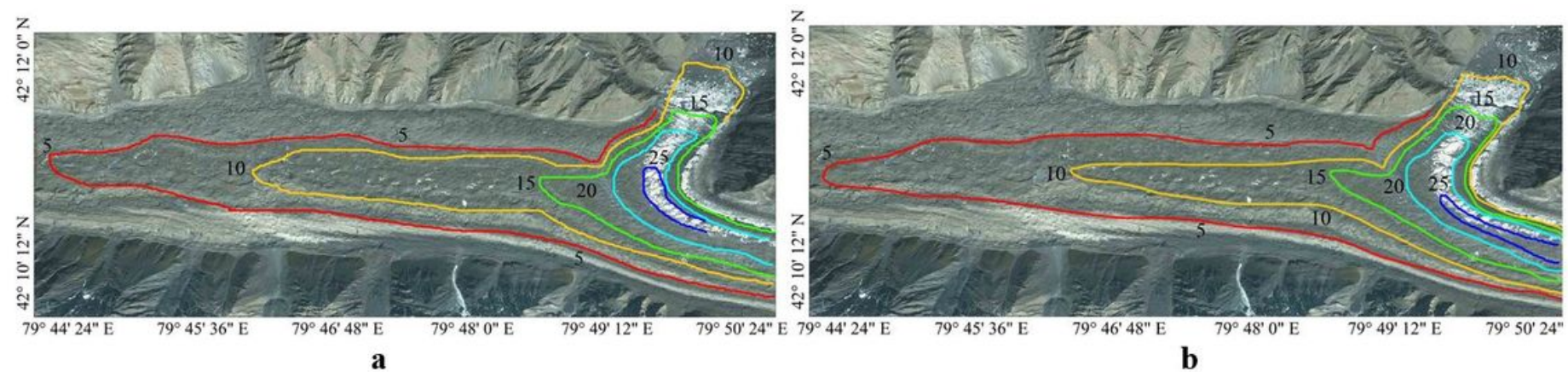

a
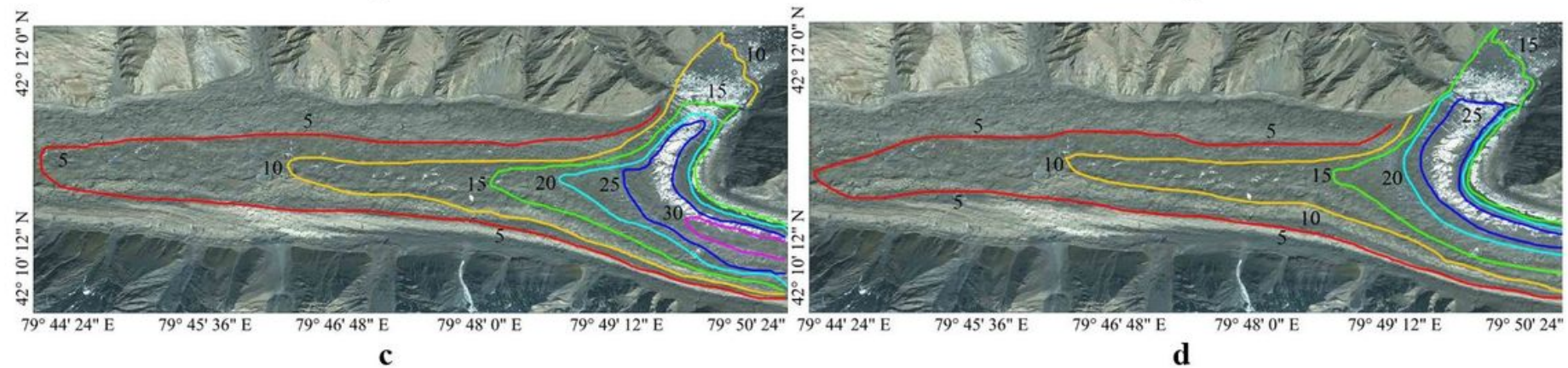

\section{Figure 8}

Contour map of glacier surface motion at the end of the glacier in 2007-2008 and 2017-2018. (a) The velocity contour map by Sentinel-1A; (b) The velocity contour map by Landsat-8; (c) The velocity contour map by ALOS/PALSAR; (d) The velocity contour map by Landsat- 5 


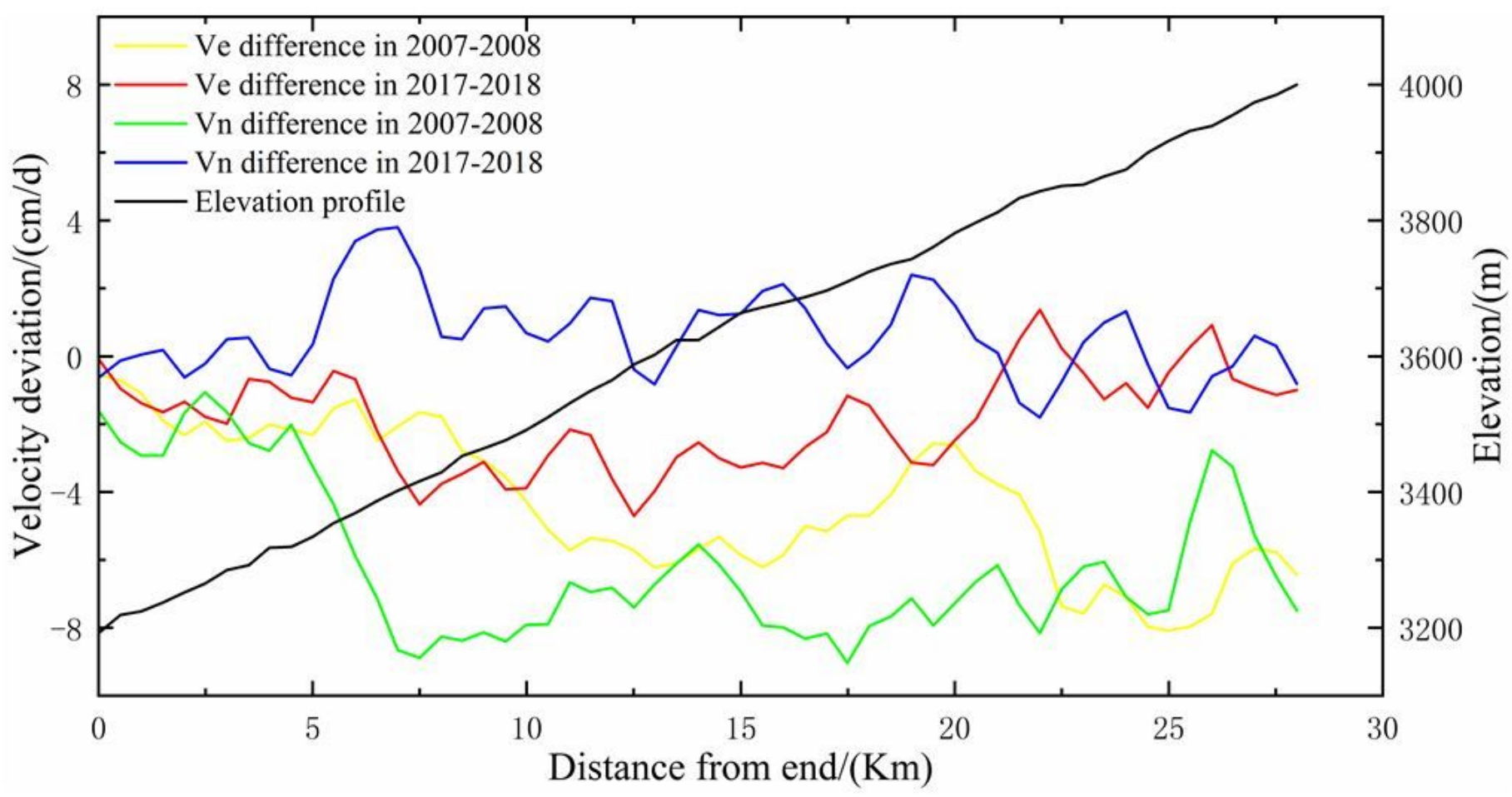

Figure 9

The glacier flows deviation and elevation profiles along the glacier surface (The 2007-2008 result was obtained from Landsat5 minus ALOS/PALSAR data, while the 2017-2018 result was obtained from Landsat8 minus Sentinel-1A data) 